\title{
MORFOGÊNESE DE TRACHYPOGON PLUMOSUS SOB CALAGEM, ADUBAÇÃO E IDADES DE REBROTA
}

\author{
MORPHOGENESIS OF TRACHYPOGON PLUMOSUS UNDER LIMING, FERTILIZATION \\ AND REGROWTH AGES
}

\author{
Costa, N. de L. ${ }^{{ }^{*}}$; Moraes, A. ${ }^{2}$; Carvalho, P.C.F. ${ }^{3}$; Monteiro, A.L.G. ${ }^{4}$; Motta, A.C.V. ${ }^{5}$; \\ Silva, A.L.P. ${ }^{6}$ e Oliveira, R.A. ${ }^{2}$
}

\begin{abstract}
${ }^{1}$ Embrapa Roraima. Boa Vista, Roraima. Brasil. *Newton.lucena-costa@embrapa.br
${ }^{2}$ Departamento de Fitotecnia e Fitossanitarismo da UFPR. Curitiba, Paraná. Brasil.

${ }^{3}$ Departamento de Zootecnia da UFRGS. Porto Alegre, Rio Grande do Sul. Brasil.

${ }^{4}$ Departamento de Zootecnia da UFPR. Curitiba, Paraná. Brasil.

${ }^{5}$ Departamento de Solos da UFPR. Curitiba, Paraná. Brasil.

${ }^{6}$ Laboratório de Nutrição Animal e Forragicultura. Universidade Tuiuti do Paraná. Brasil.

PaLAVRAS ChaVES ADICIONAIS

Área foliar. Perfilhamento. Senescência.

AdDitionAL KEYWORDS

Leaf area. Tillering. Senescence.
\end{abstract}

\section{RESUMO}

Nos cerrados de Roraima, Trachypogon plumosus é a gramínea predominante nas áreas planas e não inundáveis e a que apresenta maior potencial forrageiro para a alimentação de ruminantes. A caracterização morfogênica possibilita determinar o potencial produtivo de gramíneas forrageiras e suas bases fisiológicas permitem a proposição de práticas de manejo mais eficientes e sustentáveis. Foram avaliados os efeitos de estratégias de correção da fertilidade do solo (testemunha, calagem, adubação e calagem + adubação) e de idade de rebrota (21, $28,35,42,49,56,63,70,77$ e 84 dias) sobre a dinâmica de crescimento, rendimento de forragem e características morfogênicas e estruturais de Trachypogon plumosus. O delineamento experimental foi em blocos ao acaso com três repetições e os tratamentos arranjados em um fatorial $4 \times 10$. O aumento da idade de rebrota resultou em maiores $(p<0,05)$ rendimentos de matéria seca (MS), densidade populacional de perfilhos (DPP), número de folhas vivas (NFV), comprimento final de folhas (CFF), índice de área foliar (IAF) e taxas de alongamento (TAIF) e senescência foliar (TSF), ocorrendo o inverso quanto à taxa de aparecimento foliar (TApF). A gramínea respondeu positivamente à melhoria da fertilidade do solo. A calagem + adubação ou a adubação proporcionaram maiores $(p<0,05)$ rendimentos de MS $\left(1934\right.$ e $\left.1661 \mathrm{~kg} \mathrm{ha}^{-1}\right)$,
NFV (4,93 e 4,85 folhas perfilho-1 $),$ TApF $(0,119$ e 0,109 folhas dia-1 perfilho $\left.{ }^{-1}\right)$, TAIF $(2,14$ e $1,80 \mathrm{~cm}$ dia $^{-1}$ perfilho $\left.{ }^{-1}\right)$, CFF (18,5 e 16,1 cm), IAF $(2,42$ e 2,14), DPP (570 e 534 perfilhos $\left.\mathrm{m}^{-2}\right)$ e TSF $(0,196$ e $0,178 \mathrm{~cm} \mathrm{dia}^{-1}$ perfilho-1). Visando maximizar a eficiência de utilização da forragem produzida e reduzir as perdas por senescência foliar da gramínea, o período mais adequado de utilização de suas pastagens, durante o período chuvoso, situa-se entre 56 e 63 dias com o uso de adubação e calagem + adubação e, 63 a 70 dias para a testemunha e a calagem.

\section{SUMMARY}

In Roraima's savannas, Trachypogon plumosus is the predominant grass in plain and flood-proof areas and presents greatest forage potential for ruminant feed. Morphogenetic characterization is a very useful tool to determine the potential productivity of forage grasses and their physiological basis, allowing the proposition of management practices more efficient and sustainable. To evaluate the effects of soil fertility correction levels (control, liming, fertilization and liming + fertilization) and regrowth ages (21, 28, $35,42,49,56,63,70,77$ and 84 days) on growth dynamic, forage yield and morphogenetic and structural characteristics of Trachypogon 
plumosus. The experimental design was in randomized blocks with three replicates and treatments arranged in a factorial $4 \times 10$. Dry matter (DM) yields, tiller population density (TPD), number of live leaves (NLL), leaf blade length $(\mathrm{LBL})$, leaf area index ( $\mathrm{LAI})$, leaf elongation rate (LER) and leaf senescence rate (LSR) increased consistently $(p<0.05)$ with regrowth age, while the leaf appearance rate (LApR) was inversely proportional to regrowth age. The grass showed high responsivity to the soil fertility improvement. Liming + fertilization or fertilization alone provided higher $(p<0.05)$ DM yields (1934 and $\left.1661 \mathrm{~kg} \mathrm{ha}^{-1}\right)$, NLL (4.93 and 4.85 leaf tiller ${ }^{-1}$ ), LApR (0.119 and 0.109 leaf day $^{-1}$ tiller $^{-1}$ ), LER (2.14 and $1.80 \mathrm{~cm} \mathrm{day}^{-1}$ tiller $\left.^{-1}\right), \operatorname{LBL}(18,5$ and $16,1 \mathrm{~cm}), \operatorname{LAl}(2.42$ and 2.14), TPD (570 and 534 tillers $\left.m^{-2}\right)$ and LSR $(0,196$ and $0,178 \mathrm{~cm} \mathrm{day}^{-1}$ tiller $\left.^{-1}\right)$. To maximize the forage use efficiency and to prevent larges losses relative to senescence and leaves death, during rainy season, it is recommended at regrowth intervals of 56 to 63 days for liming + fertilized and fertilized pastures and, 63 to 70 days for control or liming pastures.

\section{INTRODUÇÃO}

Nos cerrados de Roraima, as pastagens nativas representam importante recurso forrageiro para alimentação dos rebanhos bovino e ovino. Apesar de limitações quantitativas e qualitativas, decorrentes da baixa fertilidade natural dos solos, historicamente, proporcionaram o suporte alimentar para a exploração pecuária, que passou a se constituir, ao longo dos anos, como a principal atividade econômica de Roraima (Costa et al., 2011). O excesso de lotação animal e a não reposição dos nutrientes extraídos constituem as principais causas do esgotamento da fertilidade do solo do ecossistema e, consequentemente, da redução da capacidade de suporte e do potencial produtivo das pastagens nativas ao longo dos anos (Sarmiento et al., 2006; Recio et al., 2011).

Nas áreas planas e não inundáveis dos cerrados, onde Trachypogon plumosus é a gramínea predominante, constituindo entre 80 e 90 \% da composição botânica das pastagens nativas, a produção animal pode ser muito baixa, sendo necessário entre 6 e 10 ha para a manutenção de um bovino adulto, o que inviabiliza economicamente a atividade pecuária, desde que não sejam implementadas práticas de manejo adequadas para o seu melhoramento (Costa et al., 2011). A gramínea apresenta ciclo perene, hábito de crescimento cespitoso, folhas pilosas e plantas com 40 a $80 \mathrm{~cm}$ de altura. No entanto, são escassas as informações sobre o potencial produtivo e a resposta da gramínea à melhoria das condições do ambiente de produção, notadamente quanto à correção da fertilidade do solo, visando à proposição de práticas de manejo mais sustentáveis (Costa et al., 2012).

O acúmulo de forragem está estreitamente relacionado ao estádio de crescimento da gramínea, como decorrência das alterações morfológicas e fisiológicas que afetam o balanço entre a produção e a senescência de tecidos, com reflexos na composição química, capacidade de rebrota e persistência da pastagem (Lemaire et al., 2011). Logo, deve-se procurar o ponto de equilíbrio entre produtividade e qualidade, visando assegurar os requerimentos nutricionais dos animais e garantindo, simultaneamente, a maximização da eficiência dos processos de produção, utilização e conversão da forragem produzida.

O conhecimento das características morfogênicas e estruturais proporciona a visualização da curva estacional de produção de forragem e uma estimativa de sua qualidade (Alexandrino et al., 2011), além de permitir a proposição de práticas de manejo específicas para cada gramínea forrageira (Lemaire et al., 2011). A morfogênese de uma gramínea durante seu crescimento vegetativo pode ser descrita por três variáveis: a taxa de aparecimento, a taxa de alongamento e a duração de vida das folhas, as quais, apesar de sua natureza genética, são fortemente influenciadas pelas condições ambientais (temperatura, luz, água e fertilidade do solo) e práticas de 
manejo. As interações entre estas variáveis determinam as características estruturais: número de folhas vivas/perfilho (NFV), comprimento final de folhas (CFF) e densidade de perfilhos, as quais irão determinar o índice de área foliar (IAF), ou seja, o aparato utilizado para a interceptação da radiação pelo dossel da pastagem. O NFV é decorrente da taxa de aparecimento e a duração de vida das folhas, sendo determinado geneticamente, enquanto que a taxa de alongamento foliar condiciona o CFF (Lemaire et al., 2011).

Neste trabalho foram avaliados os efeitos da calagem e/ou adubação e da idade de rebrota sobre a produção de forragem e características morfogênicas e estruturais de Trachypogon plumosus nos cerrados de Roraima, Brasil.

\section{MATERIALE MÉTODOS}

O experimento foi conduzido em pastagem nativa de $T$. plumosus, localizada em Boa Vista, Roraima (604' O e $2^{\circ} 45^{\prime}$ N), durante o período de maio a agosto de 2011, a qual não estava submetida a nenhuma prática de manejo. O clima da região, segundo a classificação de Köppen, é Aw, com precipitação anual de $1600 \mathrm{~mm}$, sendo que $80 \%$ ocorrem nos seis meses do período chuvoso (abril a setembro). Os dados de temperatura e precipitação foram coletados de pluviômetro e termômetro instalados na área experimental (tabela I).

O solo da área experimental é um Latossolo Amarelo, textura média, com as seguintes características químicas, na profundidade de $0-20 \mathrm{~cm}: \mathrm{pH}_{\mathrm{H} 2 \mathrm{O}}=5,1 ; \mathrm{P}=1,1$ $\mathrm{mg} \mathrm{kg}^{-1} ; \mathrm{Ca}+\mathrm{Mg}=0,51 \mathrm{cmol} \cdot \mathrm{dm}^{-3} ; \mathrm{K}=0,03$ $\mathrm{cmol} \cdot \mathrm{dm}^{-3} ; \mathrm{Al}=0,39 \mathrm{cmol} \mathrm{dm}^{-3} ; \mathrm{H}+\mathrm{Al}=2,43$ $\mathrm{cmol}_{\mathrm{c}}^{\mathrm{c}} \cdot \mathrm{dm}^{-3} ; \mathrm{SB}=0,54 \mathrm{cmol}_{\mathrm{c}} \cdot \mathrm{dm}^{-3} ; \mathrm{V}=18,2 \%$; matéria orgânica $=10,7 \mathrm{~g} \mathrm{~kg}^{-1}$; argila $=190 \mathrm{~g}$ $\mathrm{kg}^{-1}$; silte $=94 \mathrm{~g} \mathrm{~kg}^{-1}$; areia $=716 \mathrm{~g} \mathrm{~kg}^{-1}$. O delineamento experimental foi em blocos ao acaso com três repetições e os tratamentos arranjados em um fatorial 4 x 10. Foram avaliadas quatro estratégias de correção da fertilidade do solo (testemunha, calagem, adubação e calagem + adubação) e dez idades de rebrota (21, 28, 35, 42, 49, 56, 63, 70, 77 e 84 dias após a uniformização da pastagem a 5,0 cm acima do solo). O tamanho das parcelas foi de $5 \times 4 \mathrm{~m}$, sendo a área útil de $12 \mathrm{~m}^{2}$. A calagem foi realizada 30 dias antes do rebaixamento da pastagem, visando elevar a $40 \%$ a saturação de bases $(0,65$ tha ${ }^{-1}$ de calcário dolomítico- PRNT=100\%). A necessidade de calcário (NC) foi calculada utilizando-se a fórmula: NC ( $\left.\mathrm{t} \mathrm{ha}^{-1}\right)=$ $\left[\left(\mathrm{V}_{2}-\mathrm{V}_{1}\right) \times \mathrm{T} \times \mathrm{f}\right] \div 100$, em que: $\mathrm{V}_{1}=$ valor da saturação das bases trocáveis do solo, em percentagem, antes da correção. $\left(\mathrm{V}_{1}=\right.$ $100 \mathrm{~S} / \mathrm{T})$ sendo: $\mathrm{S}=\mathrm{Ca}^{++}+\mathrm{Mg}^{++}+\mathrm{K}^{+}$ $\left(\mathrm{cmol}_{\mathrm{c}} \mathrm{dm}^{-3}\right) ; \mathrm{V}_{2}=$ valor da saturação de bases trocáveis que se deseja; $\mathrm{T}=$ capacidade de troca de cátions, $\mathrm{T}=\mathrm{S}+\left(\mathrm{H}^{+}+\mathrm{Al}^{+++}\right)$ $\left(\mathrm{cmol}_{\mathrm{c}} \mathrm{dm}^{-3}\right)$ e, $\mathrm{f}=$ fator de correção do PRNT do calcário $(\mathrm{f}=100 / \mathrm{PRNT})$. $\mathrm{O}$ valor de $\mathrm{f}$ utilizado foi de 1,22 , pois o calcário apresentava PRNT de 82 \%. A adubação constou de $50 \mathrm{~kg} \mathrm{ha}^{-1}$ de N (ureia), $50 \mathrm{~kg} \mathrm{ha}^{-1}$ de $\mathrm{P}_{2} \mathrm{O}_{5}$ (superfosfato triplo), $50 \mathrm{~kg} \mathrm{ha}^{-1}$ de $\mathrm{K}_{2} \mathrm{O}$ (cloreto de potássio) e $30 \mathrm{~kg} \mathrm{ha}^{-1}$ de $\mathrm{S}$ (enxofre elementar), aplicados a lanço após o rebaixamento da pastagem.

Os rendimentos de matéria seca (MS) foram estimados através de cortes mecânicos, realizados a uma altura de 5,0 cm acima do solo em toda a área útil da parcela.

Tabela I. Precipitação (pp), temperaturas mínimas (t), máximas (T) e médias (Tm) e radiação solar $(R C)$ durante o período experimental. Boa Vista, Roraima. 2011. (Rainfall (pp), minimum (t), maximum $(\mathrm{T})$, and mean ( $\mathrm{Tm}$ ) temperatures, and solar radiation (RS) during the experimental period. Boa Vista, Roraima. 2011).

\begin{tabular}{lccccc}
\hline & $\mathrm{ppmm}$ & $\mathrm{t}^{\circ} \mathrm{C}$ & $\mathrm{T}^{\circ} \mathrm{C}$ & $\mathrm{Tm}^{\circ} \mathrm{C}$ & $\mathrm{RSMJ} / \mathrm{m}^{2}$ \\
\hline Maio & 692,9 & 23,0 & 30,8 & 26,9 & 376,9 \\
Junho & 383,8 & 22,7 & 31,7 & 27,2 & 381,8 \\
Julho & 389,2 & 22,2 & 32,1 & 27,1 & 432,4 \\
Agosto & 234,8 & 23,8 & 32,9 & 28,4 & 458,8 \\
\hline
\end{tabular}


O material colhido foi pesado e colocado para secar em estufa de ventilação forçada a $65^{\circ} \mathrm{C}$ por 72 horas. Para determinação das características morfogênicas e estruturais foram selecionadas quatro touceiras/parcela e marcados três perfilhos/touceira, utilizando-se fios coloridos. As avaliações foram realizadas a intervalos de três dias, quando se computava o aparecimento, o alongamento e a senescência de folhas. A taxa de alongamento foliar (TAlF) e a taxa de aparecimento de folhas (TApF) foram calculadas dividindo-se o comprimento acumulado de folhas e o número total de folhas no perfilho, respectivamente, pelo período de rebrota. O comprimento final da folha (CFF) foi determinado pela divisão do alongamento foliar total do perfilho pelo seu número de folhas. Para o cálculo da área foliar, em cada idade de rebrota foram coletadas amostras de folhas verdes completamente expandidas, procurando-se obter uma área entre 200 e $300 \mathrm{~cm}^{2}$, sendo estimada com o auxílio de um planímetro ótico eletrônico (Li-Cor, modelo LI-3100C). Posteriormente, as amostras foram levadas à estufa com ar forçado a $65^{\circ} \mathrm{C}$ até atingirem peso constante, obtendo-se a MS foliar. A área foliar específica (AFE) foi determinada através da relação entre a área de folhas verdes e a sua MS ( $\mathrm{m}^{2} \mathrm{~g}^{-1} \mathrm{MS}$ foliar). O índice de área foliar (IAF) foi determinado a partir do produto entre a MS total das folhas verdes ( $g$ de $\mathrm{MS} \mathrm{m}^{-2}$ ) pela AFE $\left(\mathrm{m}^{2} \mathrm{~g}^{-1}\right.$ de MS foliar). A taxa de senescência foliar (TSF) foi obtida dividindo-se o comprimento das folhas que se apresentavam de coloração amarelada ou necrosada pela idade de rebrota. A densidade populacional de perfilhos (DPP) foi estimada com o uso de armações metálicas de $0,25 \mathrm{~m}^{2}(50$ x $50 \mathrm{~cm})$, alocadas em quatro pontos ao acaso em cada parcela, sendo computados todos os perfilhos vivos, em cada idade de rebrota.

Os dados foram submetidos à análise de variância e de regressão considerando 5 \% de probabilidade, utilizando-se o software estatístico Sisvar (Ferreira, 2008).

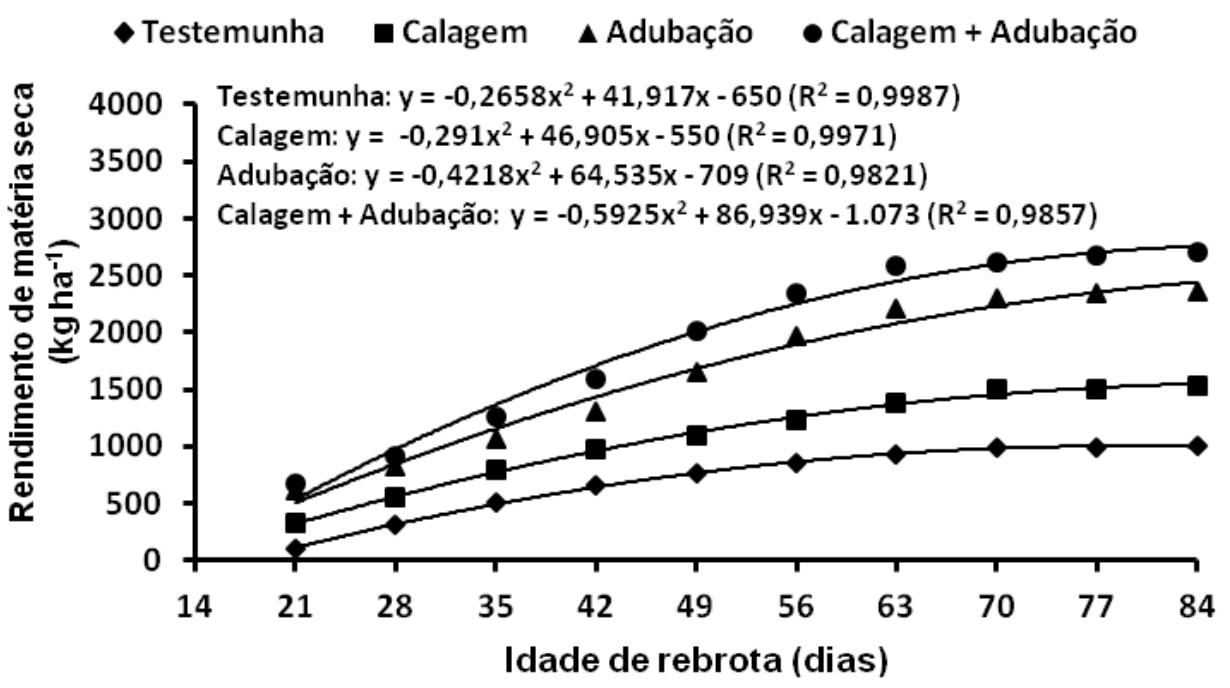

Figura 1. Rendimento de forragem de Trachypogon plumosus, em função da calagem e/ou adubação e idades de rebrota. (Forage yield of Trachypogon plumosus under liming, fertilization and regrowth ages). 


\section{RESULTADOSEDISCUSSÃO}

A gramínea respondeu positivamente à melhoria do ambiente de produção, apesar de sua boa adaptação aos solos de baixa fertilidade do Cerrado. Os maiores rendimentos de MS foram registrados com a calagem + adubação (1934 kg ha-1) e adubação (1661 kg ha-1), semelhantes entre si ( $>>0,05)$; o efeito da calagem foi menos acentuado (1087 $\left.\mathrm{kg} \mathrm{ha}^{-1}\right)$, porém superior $(\mathrm{p}<0,05)$ à testemunha $\left(710 \mathrm{~kg} \mathrm{ha}^{-1}\right)($ figura 1). Em pastagens de Trachypogon vestitus adubadas com $50 \mathrm{~kg} \mathrm{ha}^{-1}$ de $\mathrm{N}, 50 \mathrm{~kg} \mathrm{ha}^{-1}$ de $\mathrm{P}_{2} \mathrm{O}_{5}, 50 \mathrm{~kg} \mathrm{ha}^{-1}$ de $\mathrm{K}_{2} \mathrm{O}, 120 \mathrm{~kg} \mathrm{ha}^{-1}$ de calcário dolomítico e $20 \mathrm{~kg} \mathrm{ha}^{-1}$ de $\mathrm{S}$, Rippstein et al. (2001) estimaram 4550 kg ha $^{-1}$, comparativamente a 2840 e $3111 \mathrm{~kg}$ ha $^{-1}$, respectivamente na ausência de $\mathrm{N}$ ou de adubação. Utilizando níveis semelhantes de fertilização, Barger et al. (2002), em pastagens de $T$. plumosus $+T$. vestitus, constataram acréscimos de 71; 17 e $126 \%$, respectivamente para a aplicação de $\mathrm{N}(7180$ kg de MS ha-1), P + K (4900 kg de MS ha-1) e N + P + K (9490 kg de MS ha-1), comparativamente ao tratamento controle $(4200 \mathrm{~kg}$ de MS ha ${ }^{-1}$ ).

O efeito da idade de rebrota foi ajustado ao modelo quadrático e os máximos rendimentos estimados aos 78,9 $(1003 \mathrm{~kg}$ ha $\left.^{-1}\right) ; 80,6$ (1340 kg ha-1); 76,5 (1759 $\mathrm{kg} \mathrm{ha}^{-1}$ ) e 73,4 dias (2116 kg ha-1), respectivamente para testemunha, calagem, adubação e calagem + adubação (figura 1). Os valores registrados foram superiores aos relatados por Mochiutti et al. (2000) no Amapá (1124 e $1417 \mathrm{~kg} \mathrm{ha}^{-1}$, respectivamente, para $T$. plumosus roçado ou queimado anualmente e semelhantes aos reportados por Mata et al. (1985), na Venezuela, para pastagens de Trachypogon spp., submetidas a diferentes intervalos entre cortes, (1654; 2309 e $2631 \mathrm{~kg} \mathrm{ha}^{-1}$, respectivamente para cortes a cada 28, 49 e 63 dias). Para T. vestitus, Rippstein et al. (2001) constataram maiores rendimentos de MS com cortes aos 56 (3349 $\mathrm{kg} \mathrm{ha}^{-1}$ ) ou 126 dias (3124 kg ha-1), compara- tivamente a 224 dias (2867 kg ha-1).

Em todos os níveis de correção da fertilidade do solo, a TApF foi negativa e linearmente afetada pela idade de rebrota (figura 2). A calagem + adubação resultou na maior $\operatorname{TApF}\left(0,119\right.$ folhas dia ${ }^{-1}$ perfilho $\left.^{-1}\right)$, seguindo-se a adubação $\left(0,109\right.$ folhas dia $^{-1}$ perfilho $\left.^{-1}\right)$ e a calagem $\left(0,101\right.$ folhas dia $^{-1}$ perfilho $\left.^{-1}\right)$, semelhantes entre $\mathrm{si}(\mathrm{p}>0,05)$ e superiores à testemunha $\left(0,088\right.$ folhas dia $^{-1}$ perfilho $\left.^{-1}\right)$. Na ausência de limitações hídricas e nutricionais, a planta produz folhas a um ritmo determinado geneticamente em função direta da ação da temperatura ambiente sobre o meristema apical (Nabinger e Carvalho, 2009).

A TApF é a característica morfogênica mais importante, pois afeta diretamente os componentes estruturais da pastagem (CFF, DPP e NFV) e, mesmo sob condições ambientais ou de manejo desfavoráveis, seria a última a ser penalizada pela planta (Lemaire et al., 2011). A TApF resulta do balanço entre o comprimento da bainha que envolve o meristema apical e a TAlF que, respectivamente, determinam a distância que a folha tem que percorrer para emergir e a velocidade com que percorre essa distância (Lemaire et al., 2011). As TApF e TAlF podem apresentar correlação negativa, indicando que quanto maior a TApF, menor será o tempo disponível para o alongamento das folhas, o que reflete diretamente no CFF (Difante et al., 2011). Neste trabalho a correlação entre TApF e TAlF foi negativa e não significativa $(r=$ $-0,33 ; p=0,07$ ), enquanto que com o CFF foi negativa e significativa $(r=-0,56 ; p=0,01)$.

$\mathrm{O}$ número de folhas vivas (NFV) respondeu positivamente à melhoria da fertilidade do solo; os maiores valores $(\mathrm{p}<0,05)$ foram verificados com a calagem + adubação (4,93 folhas perfilho $\left.{ }^{-1}\right)$ ou adubação $\left(4,85\right.$ folhas perfilho-1 $\left.{ }^{-1}\right)$, semelhantes entre si $(p>0,05)$ e superiores à calagem (4,38 folhas perfilho $\left.{ }^{-1}\right)$ e testemunha (3,91 folhas perfilho-1) (figura 3). As plantas adubadas atingem máximo NFV mais 


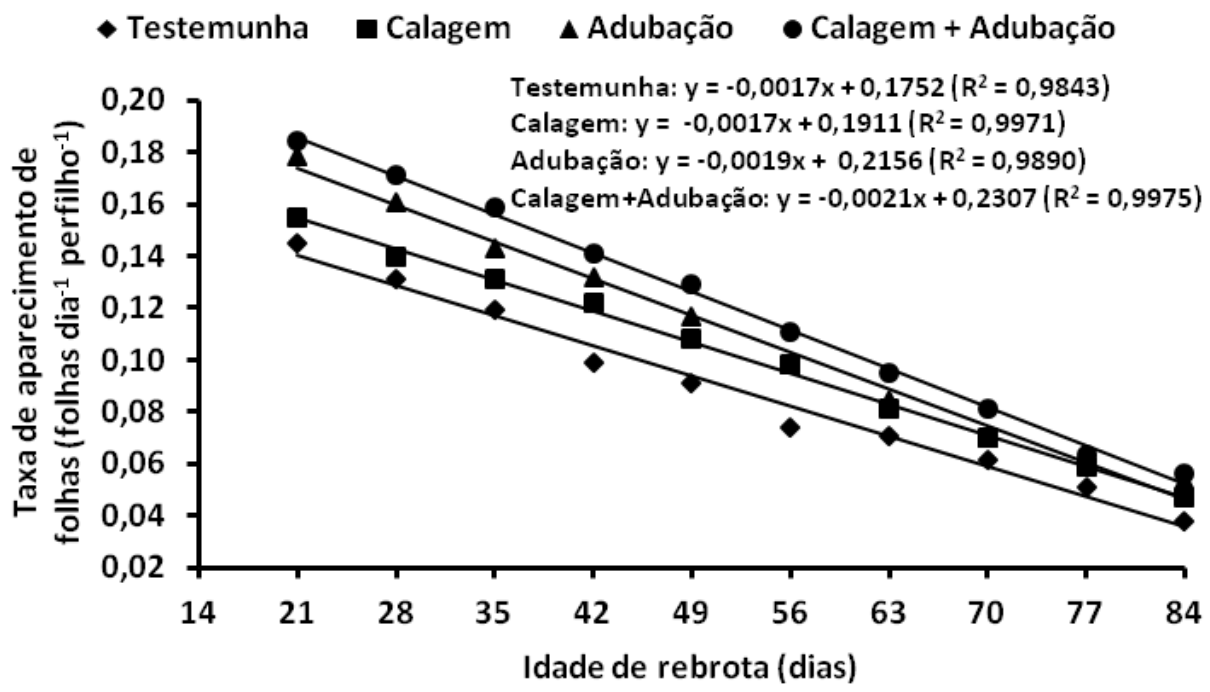

Figura 2. Taxa de aparecimento de folhas de Trachypogon plumosus, em função da calagem e/ou adubação e idades de rebrota. (Leaf appearance rate of Trachypogon plumosus under liming, fertilization and regrowth ages).

precocemente, em relação às não-adubadas, fim de evitar perdas por senescência foliar. possibilitando colheitas mais frequentes, a O efeito das idades de rebrota sobre o NFV

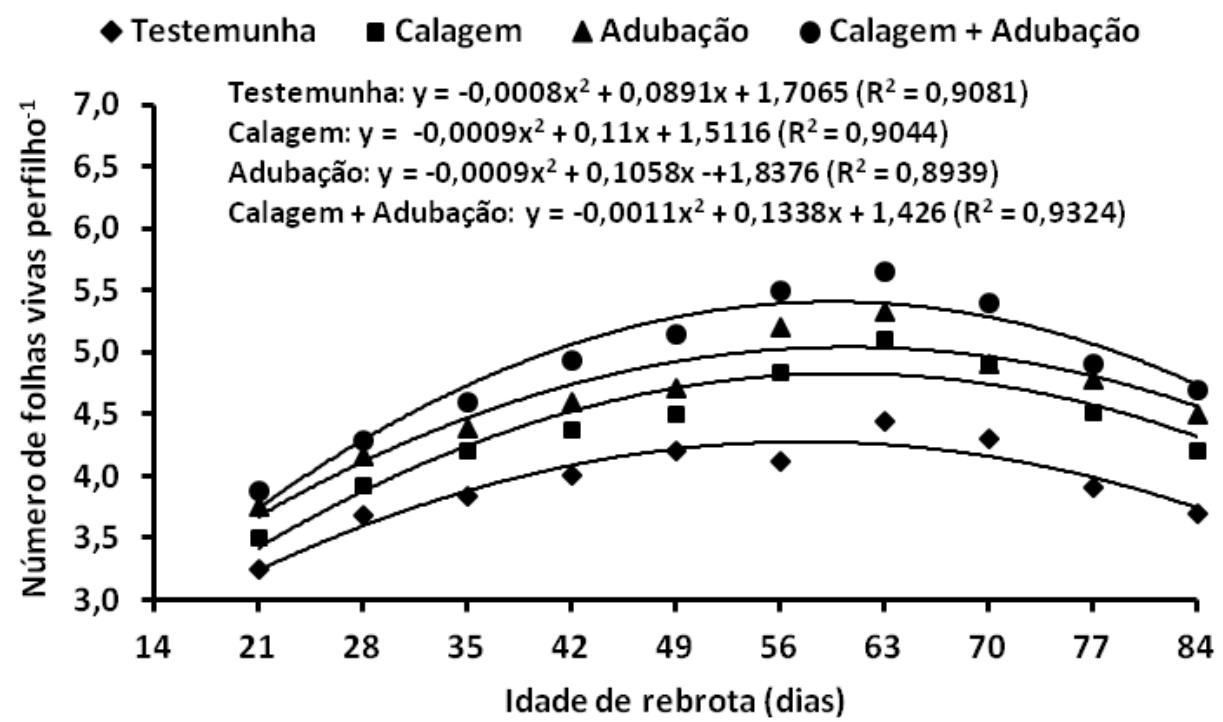

Figura 3. Número de folhas vivas perfilho-1 de Trachypogon plumosus, em função da calagem e/ou adubação e idades de rebrota. (Number of live leaves of Trachypogon plumosus under liming, fertilization and regrowth ages). 
foi ajustado ao modelo quadrático de regressão e os máximos valores obtidos aos 55,7 (4,2 folhas perfilho $\left.{ }^{-1}\right), 62,2$ (4,9 folhas perfilho-1 $^{-1}$, 58,8 (4,9 folhas perfilho-1 $)$ e 60,8 dias ( 5,5 folhas perfilho-1 ${ }^{-1}$, respectivamente para a testemunha, calagem, adubação e calagem + adubação. O NFV, constante a partir do momento em que a TSF se iguala a TApF, constitui critério objetivo e prático para a definição dos períodos de descanso na lotação rotativa e a intensidade de pastejo na lotação contínua.

A TAlF foi positivamente afetada $(\mathrm{p}<0,05)$ pela melhoria da fertilidade do solo e os maiores valores registrados com a calagem + adubação $\left(2,14 \mathrm{~cm} \mathrm{dia}^{-1}\right.$ perfilho-1 $\left.^{-1}\right)$ e adubação $\left(1,80 \mathrm{~cm} \mathrm{dia}^{-1}\right.$ perfilho-1 $\left.^{-1}\right)$, semelhantes entre si $(p>0,05)$ e superiores aos da calagem $\left(1,42 \mathrm{~cm} \mathrm{dia}^{-1}\right.$ perfilho-1 $\left.^{-1}\right)$ e testemunha $\left(1,21 \mathrm{~cm} \mathrm{dia}^{-1}\right.$ perfilho $\left.{ }^{-1}\right)$ (figura 4). A TAlF respondeu de forma quadrática às idades de rebrota e os máximos valores verificados aos 43,6 (1,34 $\mathrm{cm} \mathrm{dia}^{-1}$ perfilho $\left.^{-1}\right)$, 49,8 (1,67 $\mathrm{cm} \mathrm{dia}^{-1}$ perfilho $\left.^{-1}\right), 47,2$ (2,05 cm dia $^{-1}$ perfilho-1) e 47,9 dias $\left(2,53 \mathrm{~cm} \mathrm{dia}^{-1}\right.$ perfilho $^{-1}$ ), respectivamente para testemunha, calagem, adubação e calagem + adubação (figura 4). Os valores obtidos foram superiores aos reportados por Simoes e Baruch (1991) para T. plumosus submetido a frequências de corte de $7\left(0,70 \mathrm{~cm} \mathrm{dia}^{-1}\right.$ perfilho $\left.^{-1}\right), 14\left(0,91 \mathrm{~cm} \mathrm{dia}^{-1}\right.$ perfilho $\left.^{-1}\right)$ ou 28 dias $\left(1,57 \mathrm{~cm} \mathrm{dia}^{-1}\right.$ perfilho $\left.{ }^{-1}\right)$.

A TAlF ao responder ao suprimento de nutrientes atua como agente modificador da TApF, notadamente com a emissão de folhas sucessivas em níveis de inserção muito próximos. A TAlF é a variável morfogênica que, isoladamente, mais se correlaciona com rendimento de MS, sendo um estimador adequado do vigor de rebrota, pois juntamente com a TApF determina o tamanho da superfície fotossintetizante do dossel, diretamente por meio do CFF e indiretamente pela DPP. Apesar da natureza genética, a TAlF responde diferenciadamente às condições ambientais, notadamente temperatura, disponibilidade hídrica, fertilidade do solo e luminosidade. Com o avanço da idade de rebrota ocorre maior competição

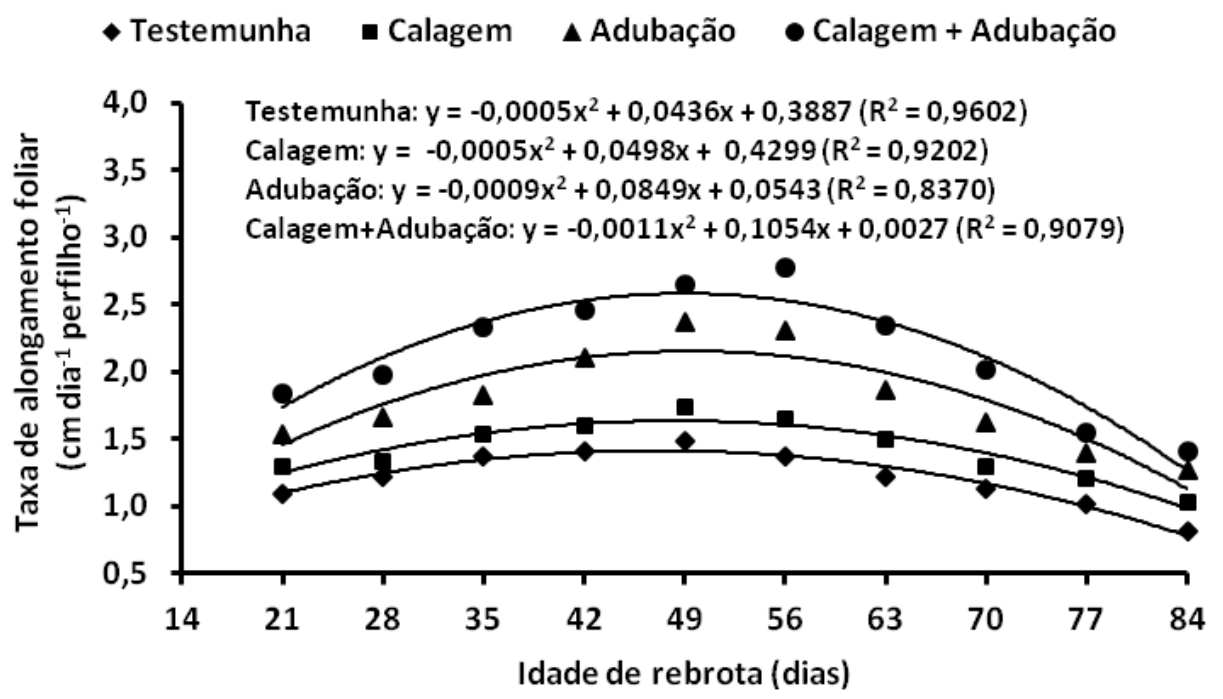

Figura 4. Taxa de alongamento foliar de Trachypogon plumosus, em função da calagem e/ ou adubação e idades de rebrota. (Leaf elongation rate of Trachypogon plumosus under liming, fertilization and regrowth ages). 
por fotoassimilados para o desenvolvimento de novos perfilhos ou estruturas reprodutivas, o que contribui para a redução na TAlF de folhas individuais. A capacidade da planta em expandir suas folhas é dependente da taxa de alongamento do meristema intercalar, zona de divisão celular, local metabolicamente ativo e de grande demanda por nutrientes (Skinner e Nelson, 1995).

A combinação calagem + adubação resultou no maior CFF $(18,5 \mathrm{~cm})$, seguindose a adubação $(16,1 \mathrm{~cm})$ e a calagem $(14,6$ $\mathrm{cm})$, semelhantes entre $\mathrm{si}(\mathrm{p}>0,05)$, sendo o menor valor registrado com a testemunha $(13,2 \mathrm{~cm})$. O efeito da idade de rebrota foi ajustado ao modelo quadrático e os máximos valores registrados aos 81,6 (16,2 cm); 79,1 (17,6 cm); 75,3 (18,9 cm) e 79,8 dias (22,1 $\mathrm{cm})$, respectivamente para testemunha, calagem, adubação e calagem + adubação (figura 5). Os valores obtidos foram superiores aos reportados por Machado (2010) para A. affinis $(5,9 \mathrm{~cm})$, A. lateralis $(9,9 \mathrm{~cm})$ e Paspalum notatum (6,9 cm). Quando as condições para o crescimento são favoráveis e constantes, a divisão celular é favorecida, possibilitando a obtenção de lâminas maiores para mesmo comprimento de bainha. A adubação ao estimular a produção de novas células, possibilita aumento na TAlF, o que constitui estratégia para alterações no CFF (Garcez Neto et al., 2002).

O CFF e o ângulo de inserção das folhas implicam na distribuição e qualidade da luz dentro de do dossel, afetando a modulação do crescimento das plantas através da produção de fotoassimilados nas fontes e sua alocação aos drenos (Lemaire et al., 2011). A redução do CFF é uma estratégia utilizada pelas gramíneas nativas dos cerrados para aquisição e conservação de água, compensando o estresse hídrico através da diminuição das perdas de água por transpiração (Sarmiento, 1992; Baruch et al., 2004). Os fatores determinantes do CFF são a TApF e a TAlF e, apesar das modificações ocorridas nestas característi-

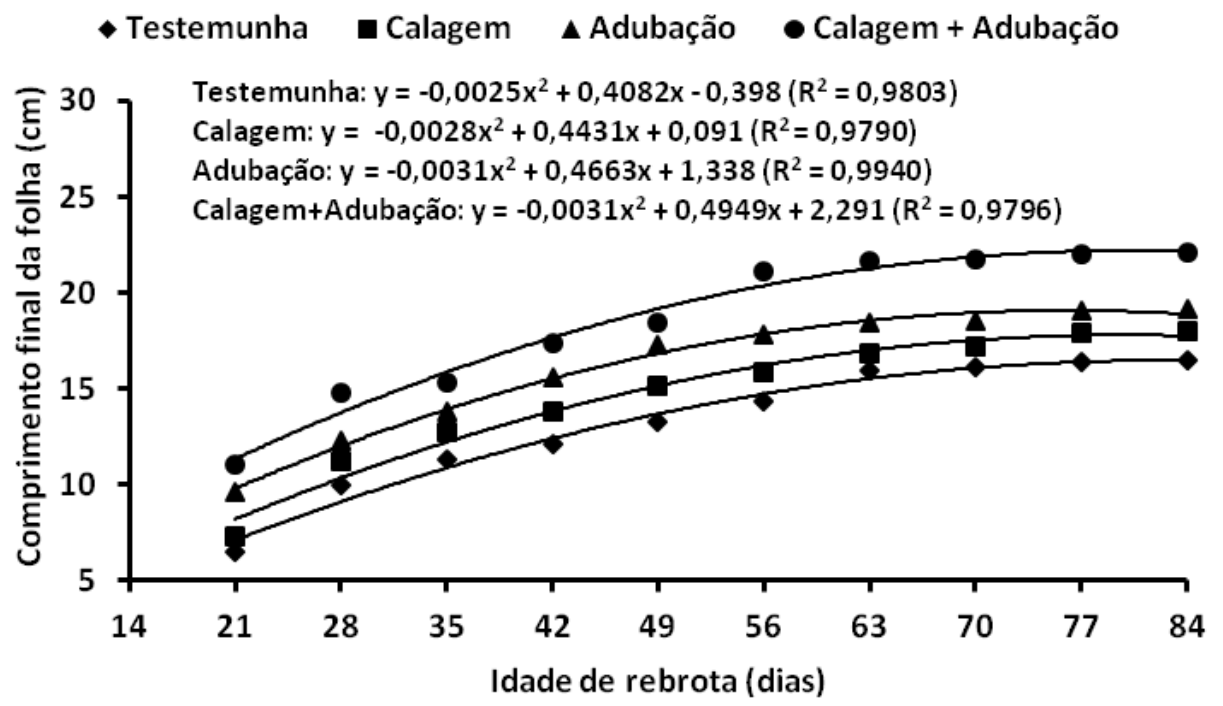

Figura 5. Comprimento final da folha de Trachypogon plumosus, em função da calagem e/ ou adubação e idades de rebrota. (Leaf blade length of Trachypogon plumosus under liming, fertilization and regrowth ages). 


\section{- Testemunha —Calagem \Adubação • Calagem + Adubação}

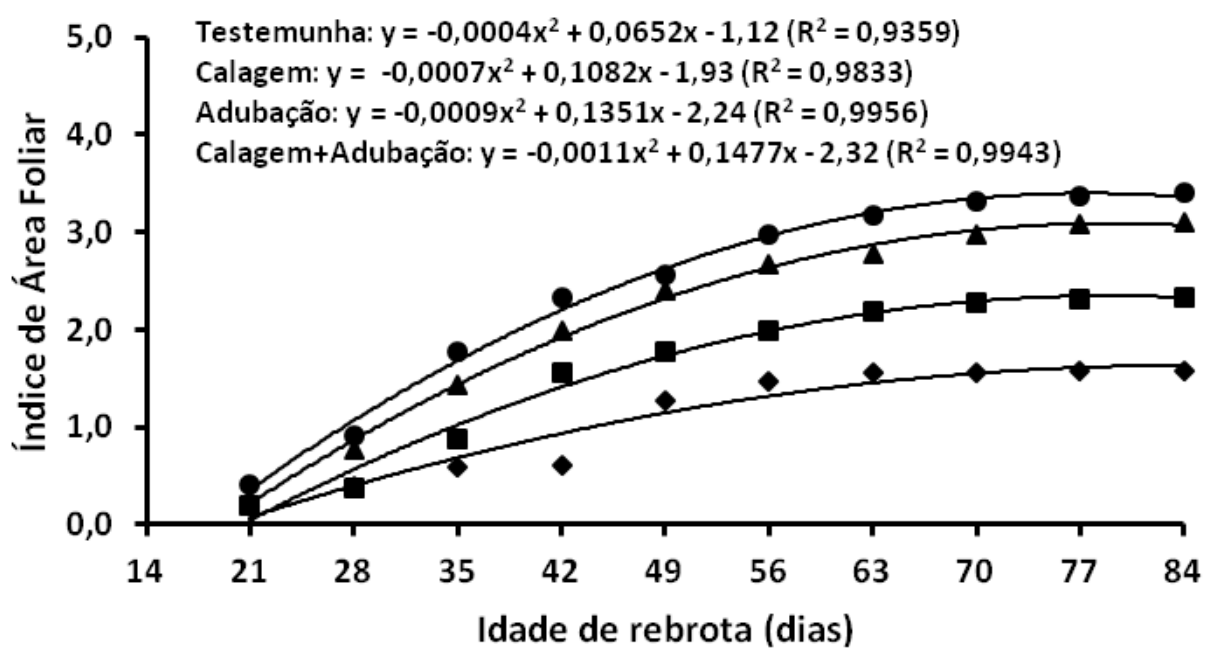

Figura 6. Índice de área foliar de Trachypogon plumosus, em função da calagem e/ou adubação e idades de rebrota. (Leaf area index of Trachypogon plumosus under liming, fertilization and regrowth ages).

cas, em função das idades de rebrota, a análise de correlação mostrou associação positiva entre CFF e TAlF $(r=0,77 ; p=0,01)$ e negativa com a TApF $(r=-0,56 ; p=0,02)$.

O IAF foi positivamente influenciado $(\mathrm{p}<0,05)$ pela calagem + adubação $(2,42)$ e adubação $(2,14)$, enquanto que a calagem $(1,59)$ e a testemunha $(1,08)$ proporcionaram os menores valores (figura 6). Como o IAF representa a síntese das características morfogênicas e estruturais da gramínea, ele reflete o balanço dos processos que determinam a oferta (fotossíntese) e a demanda (respiração, acúmulo de reservas, síntese e senescência de tecidos) de fotoassimilados, que estabelecem o ritmo de crescimento da pastagem (Nabinger e Carvalho, 2009). A ação positiva da melhoria da fertilidade do solo sobre a TAIF, o CFF e a DPP se expressa diretamente sobre o IAF da pastagem (Nabinger e Carvalho, 2009). O efeito da idade de rebrota sobre o IAF foi quadrático e os máximos valores registrados aos $81,5(1,54), 77,3(2,25), 75,1(2,83)$ e
67,1 dias $(2,64)$, respectivamente para testemunha, calagem, adubação e calagem + adubação. Os valores de IAF obtidos foram superiores aos relatados por Baruch e Bilbao (1999) para T. plumosus (1,31) e por Tejos (2002) para A. purpusii $(1,54)$, Hymenachne amplexicaulis $(1,02)$ e $P$. laxum $(0,72)$, gramíneas nativas dos cerrados da Venezuela.

O IAF foi negativamente correlacionado com a TApF ( $r=-0,65 ; p=0,01)$ e positivamente com a TAlF ( $r=0,78 ; p=0,01)$ e o CFF $(r=0,91 ; p=0,01)$, evidenciando antagonia entre TAlF e TApF e sincronia entre TAlF e CFF.

A TSF foi afetada pelos níveis de correção da fertilidade do solo e os maiores valores $(p<0,05)$ observados com a calagem + adubação $\left(0,196 \mathrm{~cm} \mathrm{dia}^{-1}\right.$ perfilho $\left.^{-1}\right)$ e adubação $\left(0,178 \mathrm{~cm} \mathrm{dia}^{-1}\right.$ perfilho $\left.^{-1}\right)$ e os menores com a calagem $\left(0,151 \mathrm{~cm} \mathrm{dia}^{-1}\right.$ perfilho $\left.^{-1}\right)$ e testemunha $\left(0,141 \mathrm{~cm} \mathrm{dia}^{-1}\right.$ perfilho-1 $^{-1}$ (figura 7). Na ausência de adubação as plantas permanecem mais 
tempo com suas folhas vivas, em detrimento do aparecimento ou expansão de novas folhas, o que contribui para o retardamento do processo de senescência. Os valores registrados foram inferiores aos reportados por Costa et al. (2012) para Trachypogon vestitus aos 45 dias de rebrota $(0,342 \mathrm{~cm}$ dia $^{-1}$ perfilho ${ }^{-1}$ ).

A relação entre TSF e idades de rebrota foi linear e positiva e o processo de senescência constatado a partir dos 21 dias de rebrota (figura 7). A senescência é um processo natural que caracteriza a última fase de desenvolvimento da folha, iniciada após completa expansão, cuja intensidade se acentua progressivamente com o aumento do IAF e do CFF, em decorrência do sombreamento das folhas inseridas na porção inferior e do baixo suprimento de radiação fotossinteticamente ativa (Nabinger e Carvalho, 2009). Quando o perfilho atinge determinado NFV ocorre equilíbrio entre a TApF e a senescência das folhas que ultrapassaram seu período de duração de vida, de modo que o surgimento de nova folha implica na senescência da folha que a precedeu, mantendo o NFV relativamente constante (Nabinger e Carvalho, 2009). As correlações entre TSF e IAF $(r=0,88$; $\mathrm{p}=$ $0,01)$ eCFF $(r=0,90 ; p=0,02)$ foram positivas e significativas, evidenciando o efeito depressivo da baixa luminosidade, o qual foi acentuado em maiores idades de rebrota. Apesar do efeito negativo sobre a qualidade da forragem, a senescência representa um importante processo fisiológico no fluxo de tecidos da gramínea, pois cerca de $50 \%$ do carbono e 80 \% do nitrogênio podem ser reciclados das folhas senescentes e utilizados pela planta para a produção de novos tecidos foliares (Lemaire et al., 2011). Em pastagens de T. plumosus, Medina (1982) constatou uma retranslocação interna de $64 \%$ do $\mathrm{N}$ das folhas senescentes para as em expansão.

As maiores DPP foram verificadas com a aplicação da calagem + adubação (570 perfilhos $\mathrm{m}^{-2}$ ) e adubação (534 perfilhos $\mathrm{m}^{-2}$ ),

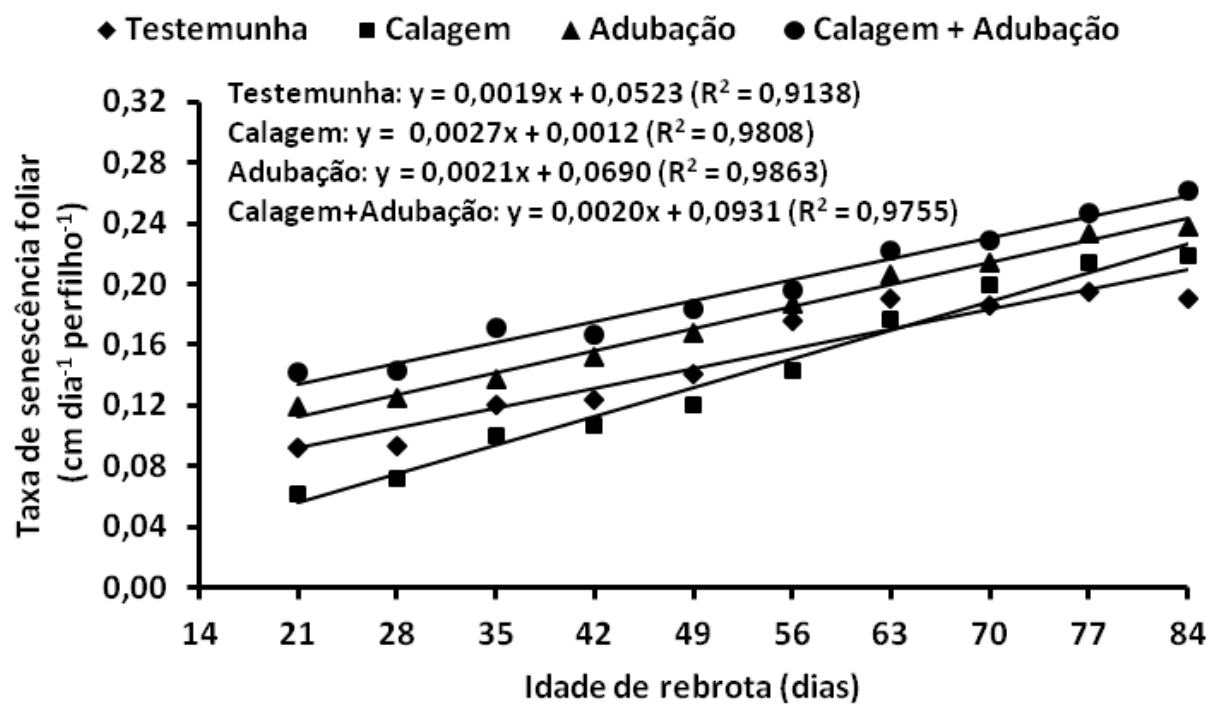

Figura 7. Taxa de senescência foliar de Trachypogon plumosus, em função da calagem e/ ou adubação e idades de rebrota. (Leaf senescence rate of Trachypogon plumosus under liming, fertilization and regrowth ages). 


\section{- Testemunha $\quad$ Calagem $\Delta$ Adubação $\bullet$ Calagem + Adubação}

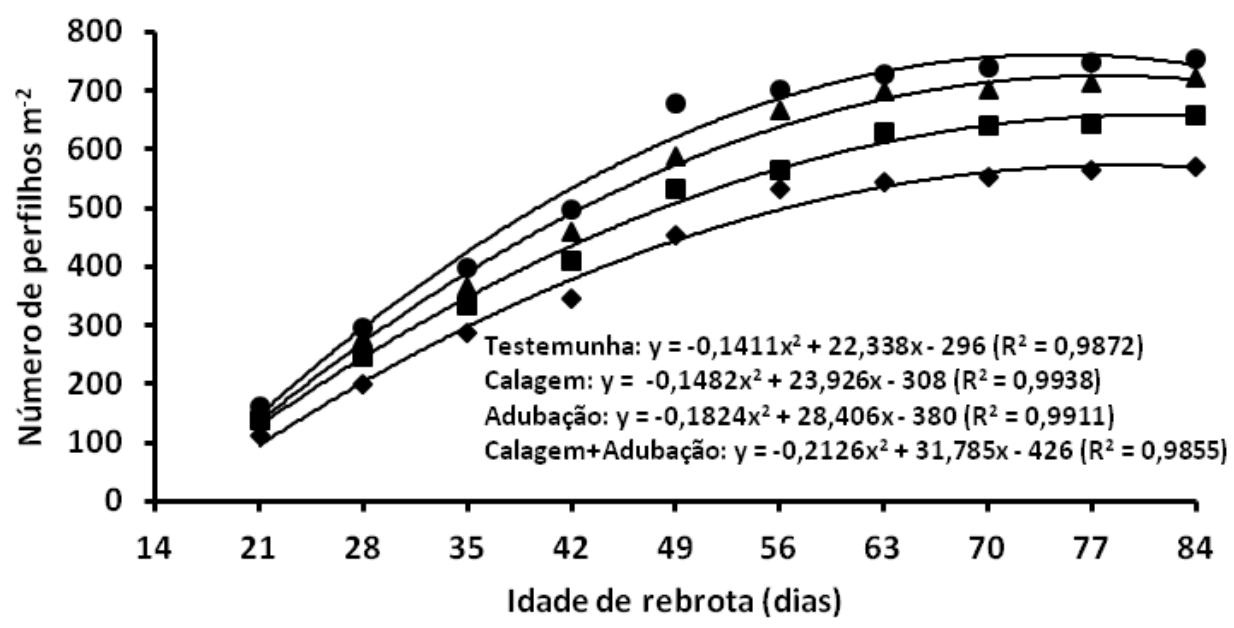

Figura 8. Densidade populacional de perfilhos de Trachypogon plumosus, em função da calagem e/ou adubação e idades de rebrota. (Tiller population density of Trachypogon plumosus under liming, fertilization and regrowth ages).

semelhantes entre si $(\mathrm{p}>0,05)$ e superiores à calagem (483 perfilhos $\mathrm{m}^{-2}$ ) e testemunha (415 perfilhos $\mathrm{m}^{-2}$ ) (figura 8). O efeito das idades de rebrota sobre a DPP foi quadrático e os maiores valores constatados aos 79,2 (588 perfilhos $\mathrm{m}^{-2}$ ); 80,7 (657 perfilhos $\mathrm{m}^{-2}$ ); 77,8 (726 perfilhos $\left.\mathrm{m}^{-2}\right)$ e 74,7 dias $(762$ perfilhos $\mathrm{m}^{-2}$ ), respectivamente para a testemunha, calagem, adubação e calagem + adubação (figura 8). Contudo, Simoes e Baruch (1991) detectaram redução na DPP de $T$. plumosus com o aumento do período de descanso (650; 430 e 410 perfilhos $\mathrm{m}^{-2}$, respectivamente para 7,14 e 28 dias). O perfilhamento estabelece gradativamente uma condição de limitação à penetração de luz, sombreando as folhas inferiores e favorecendo a senescência foliar. Quando a luz penetra o dossel, atenua-se a vermelha e a que alcança os estratos inferiores é predominantemente vermelha:extremo, caracterizada como fotossinteticamente ineficiente, reduzindo a produção de perfilhos (Nabinger e Carvalho, 2009). Se o suprimento de fotoassimilados for menor que a demanda a planta limita o número de meristemas ativos, reduzindo a DPP para manter o potencial de crescimento das folhas no perfilho principal (Lemaire et al., 2011). A DPP foi negativamente correlacionada com a TApF ( $r=-0,81 ; p=0,01)$, demonstrando o efeito restritivo da luminosidade na porção inferior da planta, o qual foi acentuado com o aumento do período de rebrota.

\section{CONCLUSÕES}

A correção da fertilidade do solo e as idades de rebrota afetam positivamente o rendimento de forragem, as taxas de crescimento e as características morfogênicas e estruturais da gramínea. Visando otimizar a eficiência de utilização da forragem produzida e reduzir as perdas por senescência foliar da gramínea, o período mais adequado de utilização de suas pastagens, durante o período chuvoso, situa-se entre 56 e 63 dias com o uso de adubação e calagem + adubação e, 63 e 70 dias quando se usa apenas a calagem ou nenhuma correção. 


\section{COSTA, MORAES, CARVALHO, MONTEIRO, MOTTA, SILVAE OLIVEIRA}

\section{BIBLIOGRAFIA}

Alexandrino, E.; Cândido, M.J.D. e Gomide, J.A. 2011. Fluxo de biomassa e taxa de acúmulo de forragem em capim 'Mombaça' mantido sob diferentes alturas. Rev Bras Saúd Prod Anim, 12: $59-71$.

Barger, N.N.; D’Antonio, C.M.; Ghneim, T.; Brink, K. e Cuevas, E.N. 2002. Nutrient limitation to primary productivity in a secondary savanna in Venezuela. Biotropica, 34: 493-501.

Baruch, Z.; Nassar, J.M. e Bubis, J. 2004. Quantitative trait, genetic, environmental, and geographical distances among populations of the $\mathrm{C}_{4}$ grass Trachypogon plumosus in Neotropical savanna. Divers Distrib, 10: 283292.

Costa, N. de L.; Gianluppi, V. e Moraes, A. 2012. Morfogênese de Trachypogon vestitus submetido à queima, nos cerrados de Roraima. Ciênc Anim Bras, 13: 41-48.

Costa, N. de L.; Moraes, A.; Oliveira, R.A.; Gianluppi, V.; Bendahan, A.B.; Magalhães, J.A. 2011. Rendimento potencial de pastagens de Trachypogon plumosus nos cerrados de Roraima.Rev. Agro@mbiente On-line, 5: 200206 (22/08/2011).

Difante, G.S.; Nascimento Júnior, D.; Silva, S.C.; Euclides, V.P.B.; Montagner, D.B.; Silveira, M.C.T. e Pena, K.S. 2011. Características morfogênicas e estruturais do capim-marandu submetido a combinações de alturas e intervalos de corte. Rev Bras Zootecn, 40: 955-963.

Ferreira, D.F. 2008. SISVAR: um programa para análises e ensino de estatística. Rev Symposium, 6: 36-41.

Garcez Neto, A.F.; Nascimento Júnior, D.; Regazzi, A.J.; Fonseca, D.M.; Mosquim, P.R. e Gobbo, K.F. 2002. Respostas morfogênicas e estruturais de Panicum maximum cv. Mombaça sob diferentes níveis de adubação nitrogenada e alturas de corte. Rev Bras Zootecn, 31: 1890-1900.

Lemaire, G.; Hodgson, J. e Chabbi, A. 2011. Grassland productivity and ecosystem services. CABI. Wallingford. $287 \mathrm{pp}$.
Machado, J.M. 2010. Morfogênese de gramíneas nativas sob níveis de adubação nitrogenada. Dissertação de Mestrado em Zootecnia. UFSM. Santa Maria. 78 pp.

Mata, D.; Moreno, E. e Rojas, N.R. 1985. Efecto de la edad sobre la composición química del Trachypogon spp. en una sabana del Sureste del Estado Guarico. Zootecn Trop, 3: 29-48.

Medina, E. 1982. Nitrogen balance in Trachypogon grasslands of central Venezuela. Plant Soil, 67: 305-314.

Mochiutti, S.; Souza Filho, A.P. e Meirelles, P.R.L. 2000. Efeitos da queima em uma pastagem nativa de cerrado do Amapá. Embrapa Amapá. Macapá. Bol Pesq, 37. 14 pp.

Nabinger, C. e Carvalho, P.C.F. 2009. Ecofisiología de sistemas pastoriles: aplicaciones para su sustentabilidad. Agrociencia, 3: 18-27.

Recio, L.P.; Lima, F.C. y Duran, A.O. 2011. Uso y manejo de forrajes nativos en la sabana inundable de la Orinoquia. Unillanos. Bogotá. $65 \mathrm{pp}$.

Rippstein, G.; Escobar, G. e Motta, F. 2001. Agroecologia y biodiversidad de los Llanos Orientales de Colombia. CIAT. Cali, Colombia. $302 \mathrm{pp}$.

Sarmiento, G. 1992. Adaptative strategies of perennial grasses in South American savannas. J Veget Sci, 3: 325-336.

Sarmiento, G.; Silva, M.P.; Naranjo, M.E. e Pinillos, M. 2006. Nitrogen and phosphorus as limiting factors for growth and primary production in a flooded savanna in the Venezuelan Llanos. $J$ Trop Ecol, 22: 203-212.

Simoes, M. e Baruch, Z. 1991. Responses to simulated herbivory and water stress in two tropical $C_{4}$ grasses. Oecologia, 88: 173-180.

Skinner, R.H. and Nelson, C.J. 1995. Elongation of the grass leaf and its relationship to the phyllochron. Crop Sci, 35: 4-10.

Tejos, R. 2002. Pastos nativos de sabanas inundables: caracterización y manejo. Megagraf. Barquisimeto. Venezuela. $111 \mathrm{pp}$. 